\title{
WRITING-INTENSIVE COURSES ACROSS THE LAW CURRICULUM: DEVELOPING LAW STUDENTS' CRITICAL THINKING AND WRITING SKILLS - A POST-EVALUATION ASSESSMENT
}

\author{
Theo Broodryk
}

$B A L L B$

Lecturer, Faculty of Law, Stellenbosch University

Melandie Buitendag

LLB LLM

LLM Writing Consultant, Faculty of Law, Stellenbosch University

\section{SUMMARY}

This article follows upon a previous article which dealt with the writing-across-thecurriculum strategy implemented at the Faculty of Law, Stellenbosch University. This article details the findings and recommendations of an outcomes evaluation conducted in respect of the strategy, commissioned by the Faculty, and deals with the design, implementation and achievement of outcomes by the strategy. It commences by considering the different components of the strategy, the implementation of these components and the relevant findings of the outcomes evaluation in this regard. Specific attention is given to the five mainstream outcomes envisaged by the Faculty through the implementation of the strategy's different but mutually complementary components. The article will conclude by making recommendations aimed at ensuring the continuous development and improvement of the strategy, not only at the Faculty, but also in an attempt to assist other law faculties in the implementation or improvement of their own writing initiatives.

\section{$1 \quad$ INTRODUCTION}

In 2011, the Faculty of Law, Stellenbosch University (Faculty), implemented a writing-across-the-curriculum strategy (Strategy). ${ }^{{ }^{2}}$ The Strategy was conceptualised and implemented essentially as a result of the apparent lack

Broodryk 'Writing-Intensive Courses Across the Law Curriculum: Developing Law Students' Critical Thinking and Writing Skills" 201435 Obiter 453. 
of critical thinking and writing skills of law graduates. ${ }^{2}$ The following quote briefly encapsulates the rationale underpinning the Strategy:

"There is a general perception that South African LLB graduates lack writing skills. Dealing with the results of an inadequate school system is not the only challenge Law faculties at South African universities face in this regard: it is namely essential that Law students learn to write academically within the Law discourse. Academic writing skills in the Law context place additional emphasis on conciseness, precision and clarity, and specifically include: arguing critically and persuasively, stating claims, hedging, logical flow, using formal register, and grammatical command. Lesley Greenbaum referred to these skills as an essential "rhetorical sensitivity to Law" (Law Teachers' Conference, January 2011). Within the context of current research on the acquisition of academic literacy...legal academic writing needs to be taught explicitly within substantive LLB modules."

This contribution follows upon a previous article, ${ }^{4}$ which article dealt with the aims of the Strategy, outlined its various components and detailed its implementation at the Faculty. This article details the findings and recommendations of an outcomes evaluation conducted in respect of the Strategy, commissioned by the Faculty, and deals with the design, implementation and the achievement of outcomes by the Strategy. ${ }^{5}$ It will commence by considering the different components of the Strategy whereafter consideration will be given to the implementation of these components and relevant findings of the outcomes evaluation in this regard. The article will conclude by making recommendations aimed at ensuring the continuous development and improvement of the Strategy. Ultimately, this article is aimed at assisting other Law Faculties in the implementation of their writing initiatives by taking account of the Strategy's post-evaluation assessment and the recommendations made in respect thereof.

\section{COMPONENTS OF THE STRATEGY}

The Strategy extends across the undergraduate LLB programme with the aim of improving students' research and writing skills. The components can be perceived as the building blocks of an all-encompassing writing-across-thecurriculum educational initiative ${ }^{6}$ Clearly defined and mutually complementary components were identified as the fundamentals of the Strategy. ${ }^{7}$ The interrelated components are aimed at achieving improvement, at entrance level, of students' general academic literacy and, at exit level, attributes

Ibid.

Quinot Proposed Evaluation Plan (2011) unpublished evaluation plan prepared for the Writing Skills Programme in the Faculty of Law, University of Stellenbosch (copy on file with author) 1.

Broodryk 201435 Obiter 453.

5 M\&ESURE Research and Evaluation Outcomes Evaluation of the Law Faculty's Legal Writing Skills Strategy (2015), unpublished report prepared for the Coordinator of the Strategy at the Faculty of Law, University of Stellenbosch, March 2015 (copy on file with author) i.

6 See Broodryk 201435 Obiter 456.

7 Broodryk 201435 Obiter 460. 
relating to communication skills. ${ }^{8}$ The Strategy consists of the following components: ${ }^{9}$

1. A first-year compulsory writing-skills development module (Writing Skills 171);

2. the introduction of writing-intensive courses into the curriculum, specifically integrated into substantive courses;

3. a standard writing framework to assess the writing skills of students (Writing Guide);

4. the appointment of Writing Consultants to conduct one-on-one consultations with the students and to assist in various aspects of students' writing; ${ }^{10}$ and

5. the continuous monitoring of the Strategy with a view to its further development and improvement.

The process of implementing the abovementioned components of the Strategy took place through specific interventions by the so-called "implementing partners". ${ }^{11}$ The implementing partners consist of Faculty lecturers, tutors and Writing Consultants as well as lecturers of the Language Centre of Stellenbosch University. ${ }^{12}$ In this regard, it may be worth mentioning that the Strategy consists of two distinct types of interventions namely, mandatory and voluntary interventions. Mandatory interventions were implemented through the compulsory writing-skills module and writingintensive modules which, in turn, required students to consult the Faculty's Writing Guide. The voluntary interventions were implemented by making a writing-consultancy service available to the Faculty's undergraduate students, to enable these students to engage the services of the Faculty's Writing Consultants, and by establishing a Faculty legal writing blog. ${ }^{13}$ These interventions (or components) will be discussed in more detail below.

The pilot phase of the Strategy commenced in 2011 and concluded in 2014. Following the pilot phase, the Faculty outsourced the evaluation of the Strategy to an external consultancy agency. The evaluation disclosed functional insights into the current state of writing development at the Faculty within the ambit of the writing-across-the-curriculum initiative. A Final Report ${ }^{14}$ (Report) was presented to the Coordinator of the Strategy (Coordinator). The content of this article is premised upon the findings and recommendations contained in the Report.

The Report specifically assessed the design, implementation and the achievement of predetermined outcomes envisaged by the Strategy. ${ }^{15}$ The

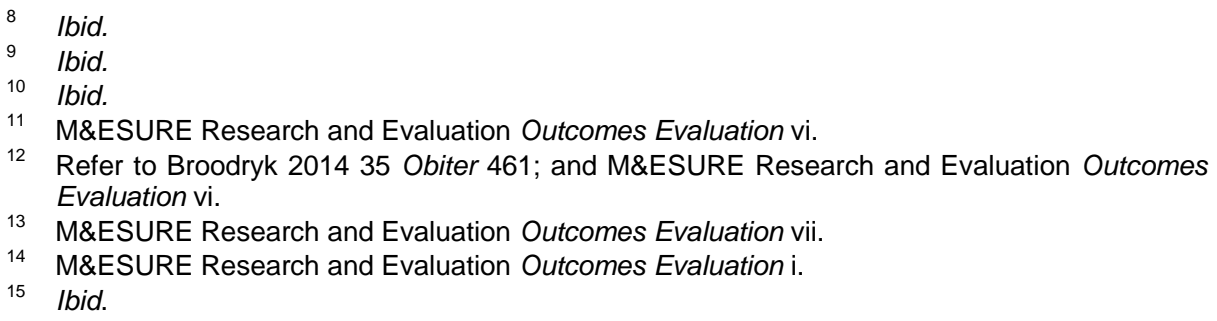


overarching goal of the evaluation was to ascertain to what degree the expected outcomes have been achieved, if at all. The five mainstream outcomes originally envisaged by the Faculty specifically pertain to visibility of improvement in students' legal-academic writing skills, the cause of improvements (if any), visibility of improvement in the answering of examination questions, any other supplementary benefits noted and the overall attitude of students towards the importance of sound legal-academic writing skills. ${ }^{16}$ Specifically, the following considerations guided the evaluation of the Strategy:

- How the Strategy's logic translates into its activities and whether these activities connect or relate to the Strategy's outcomes.

- How the Strategy as an intervention has been implemented in terms of its delivery.

- The degree to which the Strategy's expected outcomes have been achieved, which includes considering:

- whether there has been an improvement in students' legal-academic writing skills over the course of the Strategy;

- if there has been improvement in students' legal-academic writing skills, why this is the case;

- if there has been no improvement in students' legal-academic writing skills, why this is the case;

- whether there has been writing development in relation to the answering of test and examination questions;

- whether the implementation of the Strategy translates to further benefits in terms of students' learning, such as increased motivation, greater understanding of legal concepts or improved oral argumentation; and

- how the Strategy affects students' attitude towards the importance of legal-academic writing. ${ }^{17}$

The data collected by the Faculty during the course of the pilot phase essentially enabled it to engage the services of the external consultancy agency to conduct the evaluation. It is therefore prudent to, as a first port of call, deal with the continuous monitoring of the Strategy in so far as this component formed the basis of the assessment of the design, implementation and the achievement of predetermined outcomes envisaged by the Strategy.

\section{Continuous monitoring of the strategy}

From the outset it was clear that the capturing and collection of data were of vital importance to ensure accurate assessment ex post facto the pilot phase. ${ }^{18}$ The Coordinator and the University's Centre for Teaching and

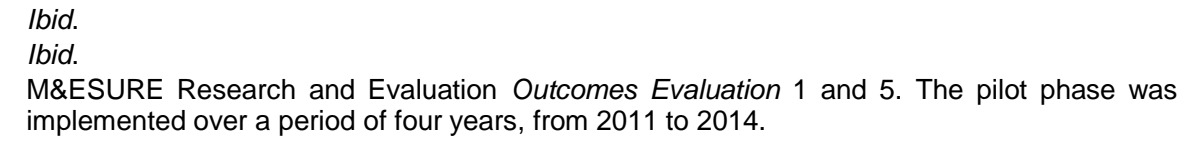


Learning were tasked with the responsibility of monitoring the Strategy. ${ }^{19}$ Various data sources were identified to be collected from the inception of the Strategy throughout the implementation thereof, which included: ${ }^{20}$

- Individual and group interviews with lecturers, students and Writing Consultants;

- electronic questionnaires completed by students;

- reports from Writing Consultants and the Coordinator;

- analysis of Writing Consultants' consultation forms; and

- analysis of samples of assignments of first- and final-year students.

To ensure the Strategy's flexibility and responsiveness, various roleplayers $^{21}$ continuously collected data which enabled the Coordinator to identify and address issues as they arose during the course of the implementation of the Strategy. ${ }^{22}$ A collaborative effort was made by the role players to collect all relevant data but, evidently, it was not without its difficulties. Role-players were unable to collect sufficient data relating to students' assignments from a predetermined test-group, comprising of a sample of first year LLB students in 2011 that were representative of the broader student groups in terms of academic achievement, gender and language. $^{23}$ The rationale was that these students' progress would be tracked during the course of their undergraduate studies to measure, when the pilot phase concluded in 2014, inter alia the extent to which these students' writing skills improved, if at all. As an alternative, a combination of first-, third- and final-year assignments were duly evaluated and assessed by a Faculty PostDoctoral student who formed part of the data collected and reported upon. ${ }^{24}$ It was also necessary to resort to anecdotal data gathered throughout various interactions with the implementing partners and students. ${ }^{25}$ Additional data was included to supplement existing data, namely, questionnaires completed by specific-year level students, ${ }^{26}$ electronic questionnaires administered to tutors involved in Writing Skills 171, lecturers in the writing-intensive modules and lecturers from the Language Centre. ${ }^{27}$ Interviews were convened with the Coordinator and relevant role players. The data was analysed by reviewing the programme documents, reports, questionnaires and interview transcripts. Despite the challenges ${ }^{28}$ associated with this component, the Report contains informative results regarding the implementation of the Strategy. These

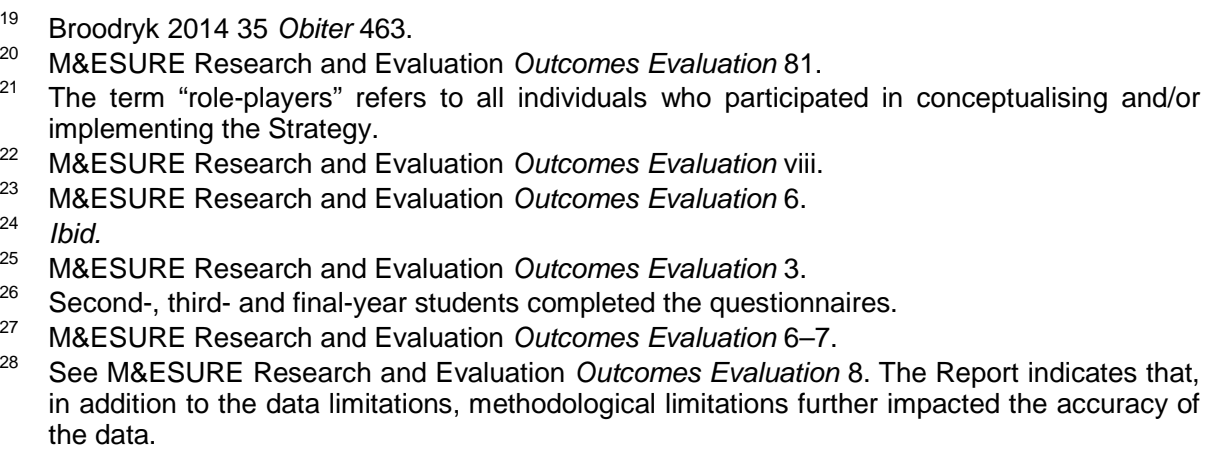

28 See M\&ESURE Research and Evaluation Outcomes Evaluation 8. The Report indicates that, in addition to the data limitations, methodological limitations further impacted the accuracy of the data. 
results will be dealt with below by considering the different components of the Strategy as mentioned above.

\section{Compulsory writing-skills module ${ }^{29}$}

In 2012, Writing Skills 171 was introduced as part of the curriculum at the Faculty as a compulsory module for first-year law students ${ }^{30}$ and duly presented as such. ${ }^{31}$ Since the inception of the Strategy the first semester of the module was presented by the Language Centre with the view to developing students' critical reading and thinking skills together with generic writing skills. ${ }^{32}$ The second semester was presented by the Faculty and focused on general skills relevant to research and writing in a legal context. ${ }^{33}$ Various implementing partners were responsible for teaching the module over the course of the pilot phase. A coordinated approach was attempted as far as possible, albeit not optimally achieved.

In the Report, it is indicated that the implementing partners and relevant role players are of the view that the value and relevance of the module unfortunately only tend to become apparent to students in their subsequent years of study as writing expectations intensify. ${ }^{34}$ They accordingly indicated, and this is reinforced by the students' feedback, that this component of the Strategy contributed the least to the development and improvement of students' writing skills. ${ }^{35}$ The difficulty level of the module, both in respect of the first and second semesters, were recorded to be on a medium level by the majority of students and fairly elementary by an alarmingly high ratio of students. ${ }^{36}$ It is also evident from the Report that students' interest levels increased after the first semester but remained low after the module progressed to the second semester. ${ }^{37}$ The Report indicates that students are inclined to be more participatory in an integrated model as opposed to a nonintegrated model. ${ }^{38}$ Unfavourable views accordingly also surfaced pertaining to the content of the module. ${ }^{39}$ Students did, however, indicate that the module assisted them, albeit nominally, to learn from the various assessment opportunities and to improve their writing skills. Unfortunately, for the majority of students the relevance of Writing Skills 171 only became apparent during their subsequent years of study. ${ }^{40}$

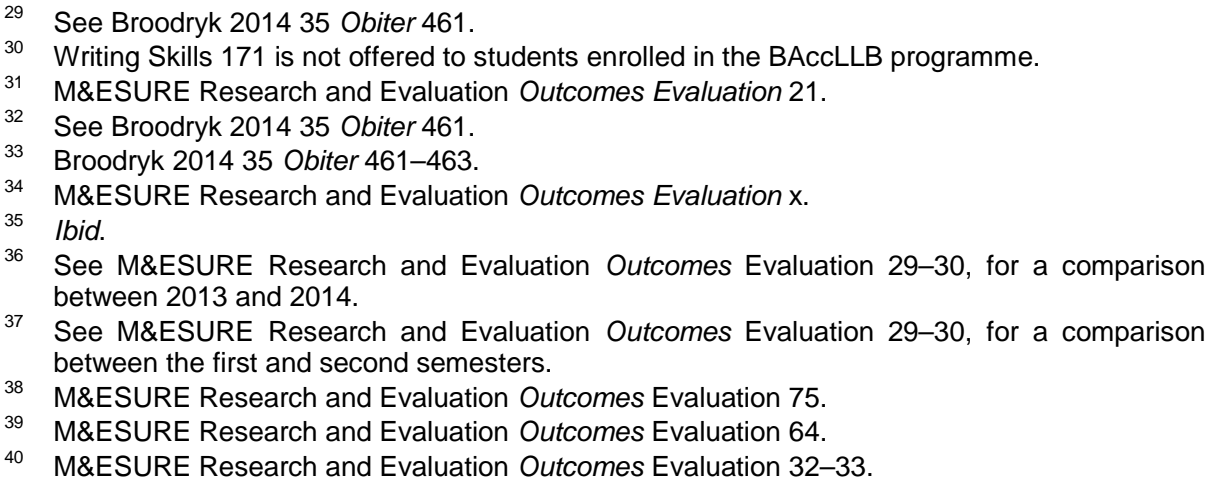




\section{Writing-intensive courses ${ }^{41}$}

Writing-intensive modules were identified as a key component in which specific attention is paid to the development of writing skills parallel to the substantive teaching in the modules. It is intended that specific aims would be set regarding students' writing skills and that each successive year would build on the skills taught and mastered in the preceding year. ${ }^{42}$ The idea to focus distinct sessions in the course on targeted writing-development skills forms part of this vision.

The first writing-intensive module was identified in 2010. Since then, the number of writing-intensive modules at the Faculty has increased exponentially. The identified modules range from first- to final-year modules to ensure an across-the-curriculum implementation of the Strategy as an educational initiative. ${ }^{43}$ These modules are aimed at supporting an approach of "writing to learn" as opposed to "learning to write". ${ }^{44}$ It is further aimed at facilitating a writing-specific result through varied assessment opportunities and, consequently, the evaluation thereof. These assessments include formal and informal writing exercises, research-intensive writing assignments, tests and formal examinations. Lecturers of the modules are encouraged to actively tailor their teaching and assessment criteria to ensure its alignment with the Strategy's objectives.

Quite predictably, the majority of the lecturers reported that their involvement in writing-intensive modules increased their workload. ${ }^{45}$ These lecturers also found it concerning that all lecturers at the Faculty are not obliged to implement the Strategy in their respective teaching methods. According to the Report, an increased commitment from lecturers not currently involved in implementing the Strategy would assist in increasing awareness of the importance of writing skills in legal education amongst the Faculty's students. It was further reported by the lecturers of writing-intensive modules that the support from the Coordinator and other Faculty members in the form of workshops and information sessions were invaluable. ${ }^{46}$

\section{Standard writing framework of the faculty ${ }^{47}$}

The idea behind this component was to compile a Faculty-specific writing framework that formulates the Faculty's writing practices and expectations. ${ }^{48}$ In 2013, a detailed Writing Guide for use by undergraduate students was published under the auspices of the Faculty. This Writing Guide is essentially

See Broodryk 201435 Obiter 463-464.

42 Broodryk 201435 Obiter 463.

43 M\&ESURE Research and Evaluation Outcomes Evaluation 34.

44 Ibid.

45 M\&ESURE Research and Evaluation Outcomes Evaluation 35.

46 M\&ESURE Research and Evaluation Outcomes Evaluation 36.

47 See Broodryk 201435 Obiter 461-462. The Writing Guide can be accessed electronically at Stellenbosch University Legal Writing "Writing Guide 2015" http://blogs.sun.ac.za/legalwriting (accessed 2015-07-21).

48 Broodryk 201435 Obiter 461. 
the tangible embodiment of the Strategy. The Writing Guide serves as a teaching-development tool that supports and reinforces the various components of the Strategy. ${ }^{49}$ It addresses the substance and form of legalwriting expectations at the Faculty. One of the goals of such an overarching writing framework is to enable the implementing partners within the particular modules, by utilising the Writing Guide, to design learning opportunities that are aligned with the Strategy. ${ }^{50}$ Importantly, it serves to create a sense of consistency and uniformity in the writing and assessment of assignments and other writing-related activities undertaken under the auspices of the Faculty. The Writing Guide has, since 2013, been consistently developed, improved, republished and redistributed to students, most recently at the commencement of $2015 .^{51}$

The implementing partners and students indicated that the Writing Guide is the most effective component of the Strategy. The Report indicates that they are of the view that it assists in improving students' overall legal-writing skills. ${ }^{52}$ Overall, the majority of students were aware of and used the Writing Guide during the course of their studies. ${ }^{53}$ Positive insights from students included the user-friendliness of the layout, easy accessibility and the fact that the information is contained in a single document. ${ }^{54}$ The implementation of the Writing Guide also resulted in an unintended consequence in that it created a platform where the implementing partners could discuss, inter alia, legal technical-writing issues. ${ }^{55}$ In the Report, the Coordinator echoed the overwhelmingly positive feedback regarding the Writing Guide received not only from the implementing partners but also from various stakeholders who attended the first national Writing Skills in Legal Education workshop hosted by the Faculty. ${ }^{56}$

This component is, however, not without its challenges. Despite the fact that the majority of students are aware of the Writing Guide, there are numerous students who fail to consult the Writing Guide or to apply its content appropriately. The Report further suggests that the Writing Guide is not in all instances applied uniformly by Faculty lecturers. This could cause confusion amongst students when completing assignments. This issue could, however, be satisfactorily addressed inter alia by the joint commitment and renewed affirmance by all the implementing partners and lecturers within the Faculty to uniformly and consistently apply the content of the Writing Guide. ${ }^{57}$

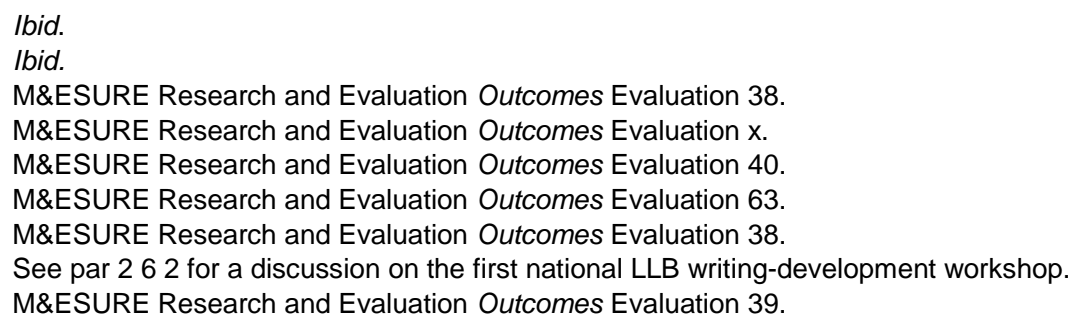




\section{Appointment of writing consultants ${ }^{58}$}

This component is aimed at providing students with an opportunity to consult with knowledgeable Writing Consultants regarding their legal writing. ${ }^{59}$ The Writing Consultants comprise legal practitioners and experts in the field of language, reading and writing. ${ }^{60}$ The roles and responsibilities of both the students and of the Writing Consultants were formalised, documented and circulated to dispel any uncertainties among implementing partners and students alike in this regard. ${ }^{61}$ The Writing Consultants, for the most part, conducted one-hour consultation sessions with students at their respective offices situated within the Faculty. Two training sessions were provided annually to the Writing Consultants duly presented by either of, or in collaboration with, the Faculty, the Centre for Teaching and Learning and the Language Centre.

This component was consistently adjusted and adapted to address emanating issues. The number of Writing Consultants reduced over the course of the Strategy's implementation. ${ }^{62}$ The reason for the reduced number of Writing Consultants was based on the demand for the availability of Writing Consultants on a full-time basis in contrast to the qualitative limitations brought about by an increased number of part-time Writing Consultants. The Writing Consultant consultation booking system has improved in leaps and bounds from the conventional method of a written-appointment roster to a more practical and effective electronic method. ${ }^{63}$

This component was not explicitly assessed by the Faculty as it does not constitute a formal curricular activity. ${ }^{64}$ The Writing Consultants were, however, required to complete a consultation form after each consultation, indicating inter alia the specific issues that were addressed during the consultation. ${ }^{65}$ The Writing Consultants indicated that students' writing improved after one-on-one consultations, especially the writing skills of those students who made use of their service on more than one occasion. ${ }^{66}$ They further reported that the service is invaluable to the effectiveness of the Strategy, and that appreciation by students of their assistance was apparent from their feedback. ${ }^{67}$ The Coordinator echoed this view. The majority of the lecturers of the writing-intensive modules also indicated that the service contributed to the effectiveness of the Strategy. ${ }^{68}$ The majority of the students indicated that they are aware of the service. However, despite such

\footnotetext{
58 See Broodryk 201435 Obiter 462-463.

59 M\&ESURE Research and Evaluation Outcomes Evaluation 41.

60 M\&ESURE Research and Evaluation Outcomes Evaluation 43.

61 Ibid.

62 M\&ESURE Research and Evaluation Outcomes Evaluation 42.

63 M\&ESURE Research and Evaluation Outcomes Evaluation 46. The online software, "Appointy", enables the Faculty to list the consultancy services from which appointments can be made by enrolled students.

64 M\&ESURE Research and Evaluation Outcomes Evaluation vii.

65 M\&ESURE Research and Evaluation Outcomes Evaluation 59.

66 M\&ESURE Research and Evaluation Outcomes Evaluation x.

67 M\&ESURE Research and Evaluation Outcomes Evaluation 66.

68 M\&ESURE Research and Evaluation Outcomes Evaluation 67.
} 
awareness, a relatively high percentage of students indicated that they have not made use thereof. ${ }^{69}$ There appears to be a tendency that once a student made use of the service, it frequently occurred that the student returned for a follow-up session. ${ }^{70}$ This ultimately aids in scaffolding upon the initial explanation and understanding of basic principles pertaining to legal writing by dealing with more complex questions and legal-writing assistance.

A radical increase of appointments occurred from the outset of the service to present, which is indicative of the desirability of this component. ${ }^{71}$ In this regard, in 2012 fewer than 100 student consultations with the Faculty's Writing Consultants were reported. In 2014, this number increased to 932 students who visited the Writing Consultants. ${ }^{72}$ Students who utilised the Writing Consultants' service valued the personal interaction, the Writing Consultants' willingness to assist and the feedback which they provided, with the result that these students felt encouraged to make continued use of the service. ${ }^{73}$ However, in some cases there were reports of inconsistencies between the advice of the Writing Consultants and the criteria set by the lecturers, resulting in uncertainty amongst students regarding the Faculty's writing expectations. ${ }^{\top 4}$ Otherwise, the implementing partners and students indicated that this component sufficiently assisted in achieving the Strategy's outcomes. ${ }^{75}$

\section{Additional resources to support the strategy}

During the course of the Strategy's pilot phase, the Faculty created and implemented additional components other than those mainstream components mentioned above. These additional components are discussed in more detail below.

\section{Legal writing blog ${ }^{76}$}

The Faculty created and launched a legal writing blog in 2013 with an underlying objective to create awareness amongst students of the importance and relevance of the theoretical fundamentals of good academic legal drafting skills. Contributions are obtained from various sources and in various forms, ranging from legal podcasts, updates on recent legal developments, practical examples of legal documents and so forth. It is worth mentioning that the Writing Guide is also obtainable in a downloadable format on the blog. The blog has further been strengthened by linking it to additional social media platforms. ${ }^{77}$ The blog is open to and accessible by the public - access is not limited to Faculty students and staff.

\footnotetext{
69 M\&ESURE Research and Evaluation Outcomes Evaluation 48.

M\&ESURE Research and Evaluation Outcomes Evaluation 49.

M\&ESURE Research and Evaluation Outcomes Evaluation 51.

Ibid.

M\&ESURE Research and Evaluation Outcomes Evaluation 64

Ibid.

M\&ESURE Research and Evaluation Outcomes Evaluation x.

The blog can be accessed at: http://blogs.sun.ac.za/legalwriting/.

77 Eg, a twitter-account was added to support the Faculty's blog.
} 
A below-average percentage of students indicated that the blog was useful to aid the improvement of their writing skills. ${ }^{78}$ This seems to be the case as a result of the general unawareness of this resource by certain implementing partners and students in general. ${ }^{79}$ Despite the afore-mentioned, a steady increase in visitors to this page was reported ${ }^{80}$ For example, in 2014 there were 24839 unique visitors who accessed the Faculty's legal writing blog. The majority of the lecturers in the writing-intensive modules indicated that the blog is a favourable platform for students to access important resources. ${ }^{81}$

The Report indicates that possibilities to increase the awareness, and consequently the effectiveness of the blog could include, amongst other things, more aggressively promoting the blog to students in the classroom and more regularly posting memorandums and feedback related to assignments on the blog. Value would also be added to the resource if more practical examples of related legal documents were posted and addressed by knowledgeable legal academics or practitioners.

\section{Writing workshop 82}

The Faculty, in an attempt to address the issues of substandard reading, writing and argumentative skills of law graduates, hosted the first national LLB Writing Skills in Legal Education workshop during September 2014. The aim was to start a conversation between law teachers and other stakeholders at a national level pertaining to the development of legal-writing skills. During the workshop, law faculties shared their approaches and experiences in developing their graduates' writing skills. Language experts and representatives from various branches of the profession conveyed their insights and respective views on the issue. At the conclusion of the workshop it was agreed that active participation and subsequent engagement among all stakeholders in legal education must be advanced and promoted with the view of improving the writing abilities of law graduates nationally. The intention was that the workshop would kindle the interests and awareness of various stakeholders in both tertiary institutions and in the private legal profession. Based on the success and positive feedback received in respect of the workshop, the Faculty will again be hosting the workshop in 2015.

\section{LLM writing consultant}

The Faculty recently ${ }^{83}$ expanded its writing consultancy service to extend to postgraduate students. This ensures that not only students whom completed

78 M\&ESURE Research and Evaluation Outcomes Evaluation $\mathrm{x}$.

79 M\&ESURE Research and Evaluation Outcomes Evaluation xi.

80 M\&ESURE Research and Evaluation Outcomes Evaluation 54.

81 M\&ESURE Research and Evaluation Outcomes Evaluation 68.

82 For a brief overview regarding the workshop, consult Quinot "First National LLB Writing Development Workshop" (undated) http://blogs.sun.ac.za/law/first-national-Ilb-writingdevelopment-workshop/ (accessed 2015-06-21).

83 At the commencement of 2015 , the Faculty appointed a Writing Consultant for postgraduate students. 
their LLB studies at the Faculty are equipped with the necessary writing skills but also that postgraduate students sourced, locally and internationally, benefit from the Strategy.

\section{OUTCOMES EVALUATION}

It is evident from the Report, taking into account the five mainstream outcomes referred to above, that the Strategy has, to a large degree, achieved the anticipated outcomes. The implementing partners indicated that improvement was indeed observable in students' overall legal academicwriting skills. ${ }^{84}$ The conclusion was derived from two main sources of evidence, namely, the assessment of student assignments at various year levels and anecdotal evidence derived from the input of implementing partners as to whether improvement was noticeable. ${ }^{85}$ Students' assignments were assessed according to an assessment scale that was developed by the Faculty by specifically taking the content of the Writing Guide into account. ${ }^{86}$ This improvement was more visible in respect of those students who relied on all the resources implemented by the Strategy as opposed to those students who failed to make sufficient use thereof. ${ }^{87}$ This improvement is attributable to the Strategy's different but mutually complementary components, although to a lesser or larger degree respectively. In this regard, it may be worth restating the value of the Writing Guide and the Writing Consultants. The students mostly reported that the Writing Guide component has been supportive of their endeavours to improve their writing skills. ${ }^{88}$ Further, it was recorded by the implementing partners that writing improvement was progressively visible after a single, but mostly multiple, one-on-one consultations with the Faculty's Writing Consultants. The students also indicated that this was the component, following the Writing Guide, which they found most valuable. ${ }^{89}$

The visibility of improvement in the answering of examination questions remains divided between the students and the lecturers of writing-intensive courses. The students, for the most part, were of the view that their "newly" acquired writing skills were valuable when writing a test or examination. The lecturers, however, remain divided about whether an improvement is indeed visible in this regard. ${ }^{90}$ Other supplementary benefits associated with the implementation of the Strategy reported by the students and Writing Consultants pertained to better oral argumentation, increased motivation and understanding of legal concepts and the improvement of critical thinking skills. ${ }^{91}$ Regrettably, some of the writing-intensive lecturers failed to echo this view. $^{92}$ Importantly, there appears to be a change in the overall disposition of students regarding the importance of acquiring writing skills - they generally

\footnotetext{
84 M\&ESURE Research and Evaluation Outcomes Evaluation ix.

85 M\&ESURE Research and Evaluation Outcomes Evaluation 56.

86 Ibid.

87 M\&ESURE Research and Evaluation Outcomes Evaluation ix.

88 M\&ESURE Research and Evaluation Outcomes Evaluation 62.

89 Ibid.

90 M\&ESURE Research and Evaluation Outcomes Evaluation xii.

91 Ibid.

92 M\&ESURE Research and Evaluation Outcomes Evaluation 77-78.
} 
appear to be more perceptive of the advantages of acquiring such skills through the implementation of the Strategy. ${ }^{93}$

\section{RECOMMENDATIONS}

The Report suggested certain measures to improve the efficacy of the Strategy which is not only meaningful to the Faculty but also other law faculties considering the implementation or the improvement of a similar strategy. The Report enabled the Faculty to gain insights into the current state and progress made in respect of the implementation of the Strategy. This forms the basis of the proposals to further develop and improve the Strategy going forward. From the outset it should be noted that the Report indicated that there has been a considerable focus on the implementation of the noncompulsory components of the Strategy. It is imperative that the main focus of the Strategy does not get derailed, but rather to stay focused on the compulsory components of the Strategy and the continuous development and improvement thereof.

Firstly the Report identified the need for the development of a monitoring and evaluation framework. ${ }^{94}$ It is clear from the data collected that there is a need for clarity regarding the implementation of the Strategy. Awareness of the Strategy within the Faculty seems to be satisfactory, albeit the implementing partners not being adequately informed about the practical functioning and implementation thereof. A clear implementation plan on how the future development and improvement is going to take place is required. Such a plan would enable the Faculty to properly monitor the Strategy. ${ }^{95}$ The proposed framework should clearly identify the main role players, their respective roles and responsibilities, and the facilitation of discussions between implementing partners and also other academic staff within the Faculty. Latter facilitation is crucial to ensure that everyone within the Faculty is on board and familiar with the Strategy in its totality. The framework will also provide the parameters to develop a comprehensive annual datacollection strategy and streamlined reporting processes. ${ }^{96}$

The "continuous monitoring" component of the Strategy was practically challenging to implement. As previously stated, ${ }^{97}$ as a result of the lack or usability of certain data specifically aimed at measuring the improvement in students' legal-writing skills, alternative anecdotal data was obtained and considered through various interactions with the implementing partners and students. There is obviously room for improving this component. In this regard, it is apparent from the Report that the lack of a clear and unambiguous monitoring and evaluation framework essentially caused the data limitations. If the data to be collected and the manner in which it is to be collected are unknown to the various role players, it cannot be expected that the collected data will suffice for the purpose of conducting a proper post-

\footnotetext{
93 M\&ESURE Research and Evaluation Outcomes Evaluation xiii.

94 Ibid.

95 M\&ESURE Research and Evaluation Outcomes Evaluation 8.

96 M\&ESURE Research and Evaluation Outcomes Evaluation xiv.

97 See par 212 above.
} 
evaluation assessment. Once the framework and parameters of the annual data-collection strategy have been established and communicated to the relevant role players, further strides can be made to fine-tune the inner workings of the evaluation component.

Secondly, there is a need for curriculum mapping with year-level writingskills outcomes. This is more commonly referred to as the "scaffolding" rationale underlying the implementation of the Strategy. The Faculty should develop tailored year-level writing-skills outcomes. Although this was envisaged and tabled as part of the implementation process, what was originally envisaged was not practically achieved in all respects. Once this has been ascertained, it is envisaged that curriculum mapping, taking cognisance of the tailored outcomes, would assist in ensuring that relevant assessment opportunities are created to ascertain whether the writing-skills outcomes have been successfully achieved. This will overtly encourage students to make use of the Strategy's components. ${ }^{98}$

Thirdly, calibration between the different components and the implementing partners should occur. For example, lecturers at the Faculty are not substantially involved in the first-year writing-skills module but, according to the Report, they should be. ${ }^{99}$ Their envisaged involvement can either be direct or indirect. Direct involvement occurs where lecturers are encouraged to get involved in the lesson planning, lecturing and assessment of the module. Indirect involvement occurs where lecturers recognise the key skills taught in the module and incorporate such skills into their respective modules, for example, in written assignments. In addition thereto, reiterating the importance of the module and encouraging students to actively work on their individual writing skills will constitute indirect involvement. Writing development and Writing Skills 171 should not be perceived and lectured in isolation of other substantive modules. A more cohesive approach between the first and second semester teachings in this module should furthermore be carried out to ensure a well-integrated year module.

The writing-intensive component of the Strategy would, according to the Report, also benefit from a more cohesive approach. There is a specific need for collaboration between the implementing partners and other lecturers currently not participating in the Strategy to strengthen the efficacy of this component. The revision and adjustment of teaching materials, with due regard to the inputs of various role players, are recommended. Commitment from an increased number of lecturers and active participation in the writingintensive modules will undoubtedly go a long way, possibly even drive the Strategy to enter into a refined phase. In addition thereto, it is recommended that the Coordinator conducts more regular one-on-one sessions with the lecturers of writing-intensive courses to assist in developing such courses to reach their full potential. The Writing Consultants have also expressed the need for increased collaboration between various role players. Opportunities

98 M\&ESURE Research and Evaluation Outcomes Evaluation xiv.

99 M\&ESURE Research and Evaluation Outcomes Evaluation ix. 
for interactive sessions with lecturers to discuss emerging issues would ensure that information is uniformly communicated to students.

Fourthly, it is recommended that more training opportunities be conducted for the implementing partners. ${ }^{101}$ Such training opportunities could include increased practical training of the tutors presenting Writing Skills $171,{ }^{102}$ additional training of the Writing Consultants and targeted-skills development initiatives for the lecturers of writing-intensive courses. It is also recommended that the Coordinator develop and facilitate more training sessions and, possibly, workshops within the Faculty to increase the skills of the implementing partners. At this stage it is imperative to consider the fact that the implementing partners are not currently a target group in the Strategy, which results in no activities and opportunities being created for them to adequately equip themselves with the necessary knowledge and, in some instances, skills to contribute effectively to the Strategy.

Fifthly, the use of the writing consultancy service by students must be streamlined. Implementing a mandatory requirement of at least one session with a Writing Consultant prior to the submission and assessment of assignments, would ensure higher quality assignments by students. This in turn, would decrease the time spent by lecturers on evaluating assignments. This would, however, entail that the voluntary intervention, that is the writing consultancy service, would become a mandatory component of the Strategy. Furthermore, limiting consultations to more intricate questions or problems would be advantageous to the advancement of the Strategy. ${ }^{104}$ To implement this proposed addition to the component would require proper training of the Writing Consultants, accurate assessment and performance accountability.

Finally, with regard to the Writing Guide, the need to improve, update, remedy and/or develop it on an ongoing basis is imperative in so far as this component is critical to the long-term sustainability of the Strategy - it captures the Strategy in a single document that forms the basis of continued empowerment of current and future implementing partners. ${ }^{105}$ This need and subsequent envisaged response tallies with the flexibility and adaptability of the Strategy.

The above recommendations can be satisfactorily addressed through the reinstatement of a committee devoted solely to the Strategy to ensure active consideration, contribution and development thereof, taking cognisance of the above recommendations. ${ }^{106}$ The committee can, inter alia, plan and implement a focused annual data-collection strategy, develop tailored yearlevel writing-skills outcomes, create and promote the necessary platforms for various role players to engage in discussions pertaining to various aspects of the Strategy, generate targeted skills-development initiatives and

100 Ibid.

101 M\&ESURE Research and Evaluation Outcomes Evaluation xv.

102 M\&ESURE Research and Evaluation Outcomes Evaluation 27.

103 M\&ESURE Research and Evaluation Outcomes Evaluation 76.

104 M\&ESURE Research and Evaluation Outcomes Evaluation xv.

105 Broodryk 201435 Obiter 462.

106 M\&ESURE Research and Evaluation Outcomes Evaluation xv. 
subsequently, consider and improve each component in accordance with the data collected.

It is evident from the Report that all components of the Strategy require revision and appropriate adjustment. However, "[i]f there is no struggle, there is no progress." ${ }^{107}$ With the benefit of hindsight, the Faculty is in a position to make specific adjustments and improvements to the Strategy to improve its overall effectiveness going forward. The post-evaluation assessment may also serve as a valuable tool for other law faculties considering, or in the process of implementing, a writing-across-the-curriculum strategy.

107 Frederick Douglass. 